\title{
Práticas e Estratégias em Diferentes Modalidades de Assentamento Rural
}

\author{
Antonio Wagner Pereira Lopes ${ }^{1}$ \\ Maristela Simões do Carmo ${ }^{2}$ \\ Sonia Maria Pessoa Pereira Bergamasco ${ }^{3}$ \\ Vera Lucia Silveira Botta Ferrante
}

Resumo: Objetivou-se proceder à análise de práticas agrícolas e estratégias constituídas por grupos de assentados da região de Araraquara e de Ribeirão Preto. Buscou-se discutir a perspectiva de um novo paradigma de produção, que venha substituir moldes comumente encontrados na produção da agricultura familiar. O objetivo deste trabalho foi realizar uma caracterização no tocante à produção, às políticas públicas e à dimensão ambiental - discutindo, através dos mesmos, perspectivas de desenvolvimento rural para os assentamentos, em modalidades distintas de assentamento: um PA e um PDS. Metodologia: foram realizadas inúmeras visitas a campo, com intuito de melhor conhecer o modo de vida dos grupos dos assentados, e aplicou-se 50 questionários - 31 no assentamento Bela Vista do Chibarro e 19 no assentamento Sepé Tiarajú. Concluiu-se que a aplicação das políticas públicas é mais rápida no PDS, as

\footnotetext{
${ }^{1}$ Possui graduação em Biologia pela FESURV - Universidade de Rio Verde-GO, (2000) e mestrado em Agronomia (Produção e Tecnologia de Sementes) pela UNESP - Universidade Estadual Paulista Júlio de Mesquita Filho (2007). Doutor em Engenharia Agrícola, na área de concentração de - Planejamento e Desenvolvimento Rural Sustentável pela Unicamp/ FEAGRI (2015).wagnerlopesgo@gmail.com

${ }^{2}$ Livre Docente pela Universidade Estadual Paulista - UNESP (2001). Professora adjunta da Universidade Estadual Paulista Júlio de Mesquita Filho. Prof ${ }^{\mathrm{a}}$ colaboradora da Universidade Estadual de Campinas. stella@fca.unesp.br.

${ }^{3}$ Professora titular da Universidade Estadual de Campinas, atuando junto à Faculdade de Engenharia Agrícola na área de Planejamento e Desenvolvimento Rural. soniaberga@yahoo.com.

${ }^{4}$ Bolsista de Produtividade em Pesquisa do CNPq - Nível 1A.. Coordenadora da PósGraduação em Desenvolvimento Territorial e Meio Ambiente. verabotta@hotmail.com.
} 
estratégias familiares são fundamentais em ambos e o processo de transição agroecológica é uma realidade.

Palavras-chave: Sistemas agrícolas; Assentamentos rurais; Políticas públicas; Estratégias; Práticas agrícolas.

Abstract: The objective was to undertake analysis of agricultural practices and strategies consist of groups of settlers of the region Araraquara and Ribeirao Preto. We tried to discuss the prospect of a new paradigm of production, which will replace molds commonly found in the production of family farming. The objective of this study was to characterize with respect to production, public policy and environmental dimension - discussing, through them, rural development prospects for settlements, in different modes of settlement: a PA and PDS. Methodology: were conducted numerous field visits, aiming to better understand the way of life of the settlers of the groups, and applied 50 questionnaires - 31 in Bela Vista settlement of Chibarro and 19 in Sepe Tiarajú settlement. It was concluded that the implementation of public policies is faster in the PDS, family strategies are fundamental in both and the agro-ecological transition process is a reality.

Key-words: Farming Systems; Rural Settlements; Public Policy; Strategies; Agricultural Practices.

\section{Introdução}

O presente artigo visa proceder à análise de práticas agrícolas e estratégias constituídas por grupos de famílias em assentamentos da região de Araraquara e de Ribeirão Preto - no tocante às práticas agrícolas, às políticas públicas e à dimensão ambiental. Este estudo teve como foco de análise dois assentamentos com datas diferenciadas de constituição, um do final da década de oitenta, outro do começo dos anos 2000. Estes são também modalidades institucionais distintas, um é um Projeto de Assentamento [PA] e o outro é um Projeto de Desenvolvimento Sustentável [PDS], respectivamente, o PA Bela Vista do Chibarro e o PDS Sepé Tiarajú.

A discussão aqui apresentada incorporou elementos sobre os rumos de modalidades diferenciadas de assentamentos, a necessidade, de se pôr em ação, práticas referidas a diferentes modelos de desenvolvimento, os constrangimentos 
detectados, as perspectivas da dimensão ambiental entrar na agenda das políticas públicas, o peso das estratégias utilizadas pelos grupos de produção e movimentos sociais na organização das cooperativas existentes no assentamento Sepé Tiarajú. Apesar da intensa e significativa produção científica voltada aos assentamentos rurais, são poucos os estudos que têm se voltado especificamente para discussão de perspectivas de diferenças a partir de modalidades de assentamentos, na área de produção, na preparação do solo, de alimentos, de recuperação de áreas degradadas, nas práticas de autoconsumo, nas atividades produtivas visando os mercados institucionais, dentre outros.

As práticas agroecológicas e a diversificação agrícola aparecem relacionadas como possíveis contrapontos às estratégias de produção a partir de uma matriz tecnológica convencional com forte propensão às culturas altamente dependentes de recursos e insumos químicos, mecânicos e genéticos. Não há neste artigo a intenção de identificar práticas sustentáveis à efetivação da Agroecologia, tal como definida no seu campo científico. Elas aparecem como expressão de práticas de outras agriculturas diferenciadas do padrão agrícola convencional. Tais práticas são detectadas nas experiências de diversificação agrícola encontradas nos assentamentos rurais. Às vezes, são pequenos sinais de uma diferenciação no manejo do solo. Outras são expressões um pouco mais evidentes de que as práticas convencionais não são as únicas existentes nos assentamentos. Nestes sinais e nestas expressões, contam conhecimentos tradicionais, troca de experiências entre os próprios assentados, o acúmulo de toda uma vida. Há pequenas e muitas vezes invisíveis dimensões de outras práticas detectadas se a investigação em torno dos sistemas de produção não ficar subordinada à visão convencional, mas incorporar outras dimensões do modo de vida.

Pretende-se uma contribuição para a análise dos rumos dos assentamentos rurais, discutindo, através dos sistemas produtivos e modo de vida de duas modalidades de assentamentos rurais, analisados além de sua expressão estritamente econômica, perspectivas dos assentados gerarem renda e terem autonomia alimentar, diversificando sua produção, buscando alternativas, ainda que tímidas, de manejo do solo e de construção sustentável de suas moradias.

\section{Metodologia e Métodos}

O acompanhamento dos grupos do assentamento Bela Vista do Chibarro e do assentamento Sepé Tiarajú desde o início da pesquisa, mostrou, passo a passo, a dificuldade no estudo do itinerário técnico de todos os produtores que 
fazem parte da pesquisa de campo, devido ao acúmulo de tarefas dos assentados, ora plantando, ora realizando colheita de produtos em época diferente dos demais produtores, ora preocupados com a escolha dos melhores caminhos da comercialização. Entretanto, a convivência nos assentamentos, a conquista da confiabilidade dos assentados, permitiu uma boa aproximação, o que foi objeto de reflexões ao longo da tese. Como "critério de amostragem", foi adotada a divisão do assentamento em grupos, a partir dos sistemas de produção e de algumas diferenciações importantes constatadas em ambos os assentamentos. Assim, a sugestão de investigar grupos de produção, produtores individualizados, assentados que não aderiram à cana transformou-se em "critério" de amostragem, expressão de uma tipologia no assentamento Bela Vista do Chibarro. Por outro lado, a existência de quatro cooperativas sugere diferenças, daí sua priorização na amostragem/tipo dos produtores do Assentamento Sepé Tiarajú. Tem-se, pois, como "amostragem", os produtores, assim distribuídos, do Assentamento Bela Vista do Chibarro: Grupo da Horta Pedra D'água - 6 produtores que representaram 100\%; Grupo de Produtores Individuais de Hortaliças - 9 produtores em um total de 15 (60\%); Grupo da Palha - 6 produtores em um total de 12 produtores $(50 \%)$; Grupos de Produtores que não Aderiram à Parceria com a Cana - 10 produtores em um total aproximado de $40^{5}(25 \%)$. Como consequência, entrevistou-se 31 produtores num total de $73^{6}$, o que representou $42,46 \%$ do conjunto dos assentados.

No Assentamento Sepé Tiarajú - município de Serrana SP - a escolha dos produtores se deu por seu pertencimento a uma das quatro cooperativas existentes. No Grupo da COOPERECOS - Foram selecionados para esta investigação dez produtores da COOPERECOS, indicados pelas lideranças e escolhidos ao longo do intenso trabalho de campo desenvolvido no Sepé Tiarajú. Esta cooperativa conta com maior número de membros comparado com outras cooperativas do assentamento. Ela é pioneira no sistema de cooperativismo no assentamento, recebendo produtos de outras cooperativas. Comercializa, repassando o montante da venda para os produtores, com papel importante de gestora da comercialização entre as cooperativas. No Sepé Tiarajú não existe agrovila, todos assentados moram em lotes onde têm suas casas construídas com material alternativo. Nas demais cooperativas, Cooperfit (com 25 membros), Cooperagrosepé (com 13 membros) e Fraterra (com 20 membros), foram

${ }^{5} \mathrm{O}$ número aproximado justifica-se face à existência de um entre e sai da cana no interior do assentamento Bela Vista. 
escolhidos nove produtores, indicados pela significativa participação em atividades agroecológicas.

Além dos questionários com perguntas fechadas e abertas aplicados aos 50 produtores, foram visitados os lotes, acompanhado o processo de preparação para a comercialização, com registros em diários de campo.

\section{Assentamento Bela Vista do Chibarro, nas Terras da Usina}

O Assentamento Bela Vista do Chibarro está localizado no município de Araraquara/SP, em terras anteriormente pertencentes à Usina Tamoio. Foi declarado de interesse social, para fins de reforma agrária pelo Decreto 97. 660, em 13 de abril de 1989. Atualmente, moram no local 223 famílias divididas no mesmo número de lotes.

Este assentamento teve, em seus momentos históricos, importância em relação à região na qual está inserido, pois, está constituído nas estruturas remanescentes de uma antiga fazenda do café, chamada Bela Vista do Chibarro estabelecida em fins do século XIX, na segunda metade da década de 1870. Em agosto de 1934, a fazenda foi agrupada às terras de uma usina de açúcar (Usina Tamoio), sendo sua estrutura física aumentada e utilizada como vila operária (prédios, habitações, mão-de-obra) que acabaram servindo à produção do açúcar. Com a decadência da usina, as áreas da fazenda foram ocupadas por trabalhadores rurais bóias-frias, e foram desapropriadas pelo Instituto Nacional de Colonização e Reforma Agrária (INCRA), no ano de 1989. No início, apesar de ter 171 famílias, apenas 69 ocuparam a área ${ }^{7}$. Essas famílias foram pioneiras e entraram no assentamento sem passar por critérios de seleção em maio de 1989. Por esse tempo, o controle do Sindicato dos Empregados Rurais de Araraquara (sempre que houve referência a esta organização foi utilizada a designação Sindicato) sobre a entrada das famílias no assentamento e tudo que acontecia na fazenda Bela Vista era quase total (ROSIM, 1997; CAIRES, 2011). Com o passar dos anos de assentamento, com os variados problemas estruturais, políticos, econômicos e sociais, constituem-se diversos grupos de produção e resistência pelas famílias assentadas no assentamento Bela Vista, modificando parcialmente os grupos iniciais, levando-se em conta a vida cotidiana na comunidade na qual se formavam relações de parentesco, amizade e vizinhança.

${ }^{6} \mathrm{O}$ número total apresentado (73) não representa o total de famílias produtoras do Bela Vista, isso porque outros grupos não entraram na amostragem pois foi priorizado basicamente o critério da diversificação da produção. 
É importante ressaltar que o assentamento está cercado por usinas, as mais próximas são as Usina Zanin e a Corona, mas, como se não bastasse, Araraquara é uma das maiores regiões sucroalcooleiras do país. Esta característica regional favoreceu a entrada da cana no assentamento, pois aqui essa cultura é um produto de fácil comercialização. No entanto, Ferrante (2004) afirma que o desenvolvimento dos assentamentos tem na problemática integração ao sistema produtivo da cana-de-açúcar, o maior polo de conflito, de certa maneira fechando um ciclo de contradições sociais que tem justamente na economia sucroalcooleira, seu principal eixo.

Nos anos iniciais do assentamento, o órgão federal responsável esteve ausente, deixando por conta do Instituto de Terras do Estado de São Paulo (ITESP), a responsabilidade pela assistência técnica. A falta de acompanhamento ocasionou problemas que poderiam ter sido evitados se houvesse, na trajetória do assentamento, uma fiscalização da conduta dos assentados e incentivo a alternativas produtivas por meio de políticas públicas. Em 2007, apenas alguns assentados resistiam à cana. O INCRA, dando sequência às ações de regularização, no dia 10 de dezembro do mesmo ano, cumpriu 11 mandados de reintegração de posse, sendo cinco lotes ocupados irregularmente (compra e venda de lotes).

Apesar do rompimento parcial da parceria com a usina, a colheita da cana continuou sendo feita pela mesma usina sob autorização do órgão gestor do assentamento. Entretanto, desde 2008, os assentados vivem a angústia de saber se poderão ou não cortar a cana do seu lote. Apesar da tentativa de regularização, a situação da cana ainda é muito caótica, com a frustração das várias tentativas de acordo/solução, as quais serão detalhadas, a seguir, no período mais recente do assentamento Bela Vista. Não obstante, alternativas estão sendo desenvolvidas no assentamento, merecendo destaque as experiências coletivas de cunho familiar na produção de hortaliças. Estas experiências têm apontado outro horizonte para os assentados, pois apresentam formas de desenvolvimento que são coerentes com as perspectivas da agricultura familiar. Todavia, mesmo tendo encontrado um caminho possível para a coletividade, os assentados ainda estão sofrendo com a falta de políticas públicas que pudessem fomentar perspectivas diferenciadas para os agricultores (PESQUISAINCRA/UNIARA, 2010 / 2011).

\footnotetext{
${ }^{7}$ Ver a respeito em Rosim, L. Nas terras da Usina, o fazer-se de um assentamento. Dissertação de Mestrado- Programa de Sociologia -FCL/UNESP. Araraquara, 1997.
} 


\section{Caracterização do Assentamento Sepé Tiarajú: o Primeiro PDS Instituído no Estado de São Paulo}

O Assentamento Sepé Tiarajú, criado em 2004, está localizado entre os municípios de Serrana e Serra Azul, distante aproximadamente $30 \mathrm{~km}$ da cidade de Ribeirão Preto, o principal município da região. A origem do nome Sepé Tiarajú se reporta a um índio, herói guarani, missioneiro, rio-grandense e, agora, herói brasileiro. $\mathrm{O}$ assentamento abrange atualmente oitenta famílias, em uma área de 814 ha, ocupada historicamente pela cultura da cana-de-açúcar.

Este assentamento já vem sendo estudado por muitos pesquisadores sob diferentes aspectos. Contudo, cabe destacar os estudos desenvolvidos por Luís Otávio Ramos Filho, pesquisador da EMBRAPA Meio Ambiente, do Grupo de Agroecologia, também da EMBRAPA Jaguariúna, que repousa sob a perspectiva da sustentabilidade ambiental e econômica dos sistemas agroecológicos de produção da comunidade; por Rosemeire Scopinho, professora do departamento de Psicologia da UFSCAR, que busca analisar o processo organizativo do assentamento à luz, especialmente, das trajetórias dos sujeitos envolvidos; por Maia (2013) que estudou a interferência do PAA no projeto Sepé Tiarajú, concluindo ser o programa um elemento que alavanca a produção e reprodução da vida. Tais pesquisadores, assim como outros têm acompanhado o assentamento desde o início de sua formação, foram fontes indispensáveis para este trabalho.

Em 1999, o Ministério do Meio Ambiente e o Ministério Extraordinário de Política Fundiária publicaram a Portaria Interministerial de número 01, visando a integração e criação de instrumentos legais e administrativos de política fundiária e ambiente, visando a instituição de um modelo de reforma agrária sustentável e de proteção ao meio ambiente, em especial na Amazônia (INCRA; MMA; CNS, 2000).

Do ponto de vista ambiental, o PDS é uma excelente oportunidade no campo das políticas públicas voltadas para garantir a transição para uma produção agropecuária sustentável. Os PDS's buscam ampliar o leque e o enfoque do desenvolvimento produtivo dos assentamentos, incluindo o componente ambiental no planejamento da geração de ocupações produtivas e de renda, inserindo os diferentes tipos e denominações de Sistemas de Produção Sustentáveis, com ou sem a criação de animais (ALY JÚNIOR, 2011, p. 293). Dessa maneira, o PDS busca incluir as áreas florestais (nativas ou mesmo exóticas) no sistema produtivo e que estas sejam preservadas e manejadas. Isto para que mostre a sua importância para o microclima, a manutenção da agrobiodiversidade, a proteção do solo e dos recursos hídricos (preservando e recuperando nascentes de água). 
Parte-se do pressuposto de que a integração entre preservação e exploração econômica não degradadoras do meio ambiente possibilitarão construir sistemas produtivos sustentáveis e economicamente rentáveis.

Portanto, o PDS é uma normativa do INCRA criada a partir da solicitação dos movimentos sociais, no sentido de conciliar o assentamento humano de populações não tradicionais, em áreas de interesse ambiental, com a promoção do desenvolvimento sustentável. Esta modalidade de assentamento foi criada através da Portaria/INCRA n. ${ }^{\circ}$ 477/99, que define o Projeto de Desenvolvimento Sustentável como uma modalidade de projeto de assentamento, de interesse sócio-econômico-ambiental, destinado às populações que já desenvolvem ou que se disponham a desenvolver atividades de baixo impacto ambiental, baseado na aptidão da área (ALY JÚNIOR, 2011).

O assentamento Sepé Tiarajú, assim como tantos outros assentamentos, é resultante de um processo histórico de mobilização e de lutas sociais travadas pela terra. No início dos anos 90, o MST buscou expandir sua atuação para a região de Ribeirão Preto, por diversas razões e, até mesmo por divergências dentro da própria esquerda atuante no cenário de luta pela terra na região.

A desapropriação da Fazenda Santa Clara foi, portanto, fruto de muitas lutas articuladas a partir das ações das famílias acampadas, dirigentes do MST, militantes da reforma agrária da região - articulados pelo grupo Amigos do MST, bem como do Instituto Nacional de Colonização e Reforma Agrária (INCRA), pela Superintendência Regional de São Paulo.

De acordo com Scopinho (2009) as condições essenciais para a oficialização do PDS Sepé Tiarajú foram: conceder o título de posse (e não de propriedade) da terra para evitar a venda e o arrendamento; produzir de modo cooperado e agroecológico para recuperar a área degradada pela monocultura da cana; criar uma empresa social para receber os recursos financeiros e realizar a prestação de contas para o Estado; formar um comitê gestor do assentamento composto por representantes dos poderes públicos estaduais e municipais, dos assentados, de organizações não governamentais locais e do INCRA.

Atualmente, as oitenta famílias assentadas, nucleadas socialmente como fora proposto pelo TAC, ou seja, em quatro Núcleos de Moradia - Chico Mendes, Dandara, Paulo Freire e Zumbi dos Palmares - experimentam uma nova forma de organização interna, que orienta as dimensões da vida política, econômica, produtiva, social e cultural das famílias. Essa nova organização interna conta com a formação de quatro organizações sociais (associações e cooperativas) COOPERECOS, COOPERAGROSEPÉ, FRATERRA e COOPERFIT, que 
por sua vez expressam as principais concepções - divergentes, porém, não antagônicas - acerca do desenvolvimento do assentamento e congregam as principais lideranças da comunidade (MAIA, 2013).

\section{Resultados e Discussões}

Esta seção discute o resultado das diferentes estratégias de pesquisa aplicadas no Assentamento Bela Vista do Chibarro e no Assentamento Sepé Tiarajú em relação ao sistema de produção, às políticas públicas e à dimensão ambiental.

\section{O que os dados revelam para o Assentamento Bela Vista do Chibarro}

Um dos objetivos desta seção é analisar as condições infraestruturais necessárias à qualidade de vida da população assentada, bem como o conjunto de políticas públicas (que sempre estão em presença com a infraestrutura e umas com as outras) implementadas (GOMES; FERRANTE, 2012). Entre as variáveis analisadas estão a política de crédito, a política de assistência técnica, as políticas de comercialização e escoamento e a política de infraestrutura social (entendidas neste trabalho como a execução de ações de infraestrutura social).

A política creditícia pode ser acessada para investimentos em habitação, custeio e operacionalização do sistema produtivo. Os programas mais acessados pelos assentados no Brasil são o PRONAF e o Fundo de Expansão do Agronegócio Paulista(PESQUISAUNIARA/INCRA, 2011).

Apesar das inúmeras linhas de financiamento disponibilizadas aos assentados e produtores rurais, no assentamento Bela Vista, apenas 16\% dos produtores lançaram mão de financiamento para implantar o sistema produtivo ao longo da trajetória do assentado no assentamento, 65\% afirmaram ter implantado o sistema com recursos próprios e $19 \%$ preferiram não responder ao questionamento. A figura 1 apresenta a relação das linhas que foram acessadas pelos assentados. 
Figura 1 - Linhas de crédito acessadas pelos produtores entrevistados no Assentamento Bela Vista.

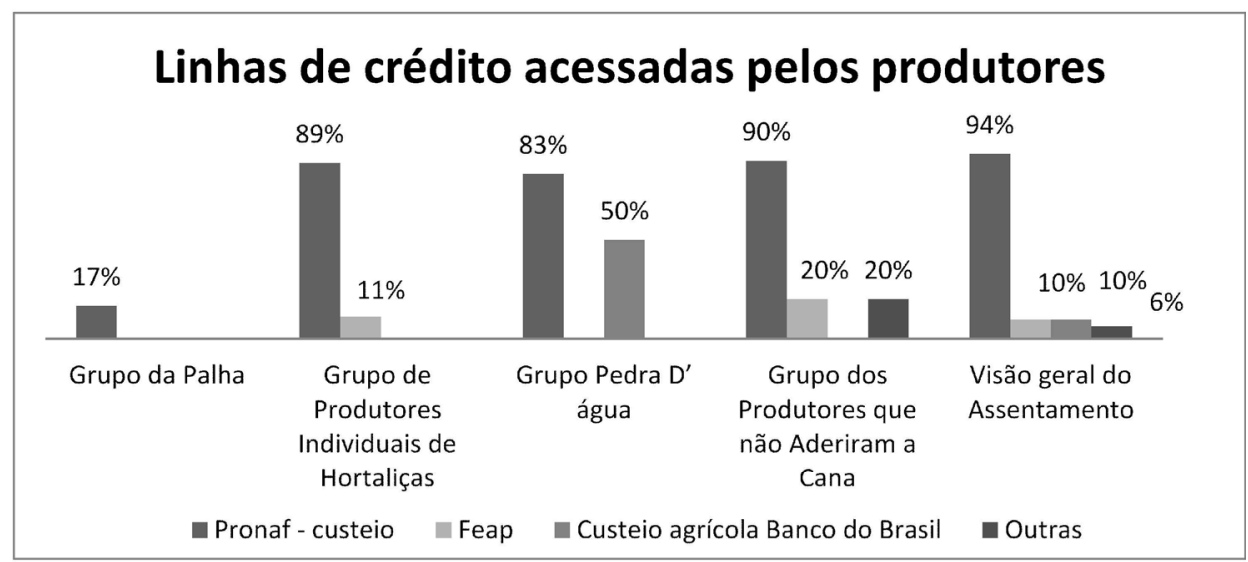

Outra variável investigada por esta seção foi a política de assistência técnica, constatou-se que os assentados tiveram acesso à assistência, teoricamente, disponibilizada pelo INCRA ${ }^{8}$, sendo que a média de produtores que recebeu assistência foi correspondente ao percentual de $53 \%$. Ficou claro nas entrevistas, que o grupo da Palha e o grupo que não aderiu à cana foram pouco beneficiados por esta política, apenas $20 \%$ de seus produtores. No lado oposto, visualizouse o grupo Pedra D'água em que todos os produtores foram capacitados via assistência técnica.

A outra variável analisada foi o acesso às políticas de comercialização. Os resultados das entrevistas são apresentados na figura 2 .

\footnotetext{
${ }^{8}$ Durante muito tempo, de 1989 ao início dos anos 2000, o INCRA permaneceu ausente da gestão da assistência técnica, sendo o Itesp o responsável por esta política. Ressalta-se ainda que o fato de ter assistência técnica não significa que ela seja considerada adequada, efetiva ou que tenha ido ao encontro das necessidades dos assentados. A história do assentamento registra muitos momentos de conflitos com os órgãos gestores.
} 
Figura 2 - Programas de apoio à comercialização acessados pelos entrevistados do Assentamento Bela Vista.

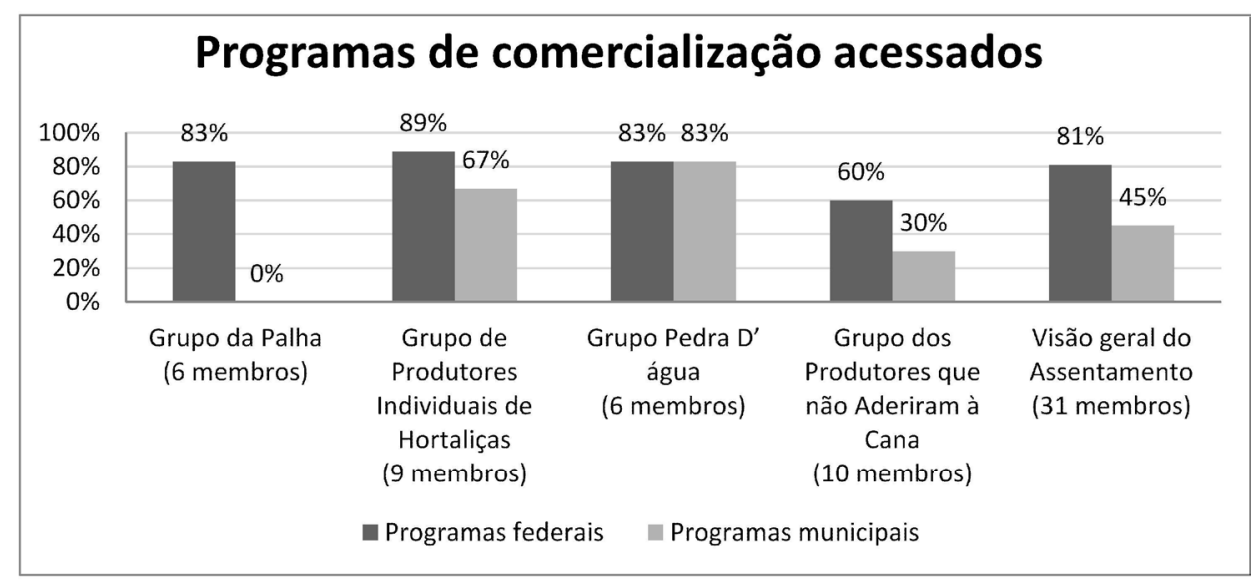

Investigou-se também o acesso às políticas de infraestrutura social. A tabela 1 apresenta uma síntese do nível de satisfação dos agricultores assentados em relação às políticas sociais e de infraestrutura ofertadas pelo poder público.

Tabela 1 - Análise da oferta de políticas de infraestrutura social no assentamento Bela Vista.

\begin{tabular}{lccccc}
\hline $\begin{array}{l}\text { Variável em } \\
\text { análise }\end{array}$ & $\begin{array}{l}\text { Grupo da } \\
\text { Palha }\end{array}$ & $\begin{array}{l}\text { Grupo de } \\
\text { Produtores } \\
\text { Individuais } \\
\text { de }\end{array}$ & $\begin{array}{l}\text { Grupo } \\
\text { Pedra } \\
\text { Hortaliças }\end{array}$ & $\begin{array}{l}\text { Grupo dos } \\
\text { Produtores } \\
\text { que não } \\
\text { Aderiram } \\
\text { à Cana }\end{array}$ & $\begin{array}{l}\text { Visão geral } \\
\text { do } \\
\text { assentamento }\end{array}$ \\
\hline $\begin{array}{l}\text { Estrada em } \\
\text { condições }\end{array}$ & $83 \%$ & $89 \%$ & $100 \%$ & $90 \%$ & $94 \%$ \\
$\begin{array}{l}\text { Transporte para } \\
\text { a cidade }\end{array}$ & $67 \%$ & $89 \%$ & $100 \%$ & $60 \%$ & $74 \%$ \\
$\begin{array}{l}\text { Comunicação } \\
\text { telefônica }\end{array}$ & $83 \%$ & $89 \%$ & $83 \%$ & $100 \%$ & $87 \%$ \\
$\begin{array}{l}\text { Internet } \\
\text { Educação }\end{array}$ & $0 \%$ & $22 \%$ & $0 \%$ & $0 \%$ & $6 \%$ \\
Posto/saúde & $100 \%$ & $100 \%$ & $100 \%$ & $100 \%$ & $100 \%$ \\
\hline & $100 \%$ & $100 \%$ & $100 \%$ & $100 \%$ & $100 \%$ \\
\hline
\end{tabular}


Em relação ao sistema de produção, foram discutidos os resultados, investigadas as metodologias de cultivo de vegetais e a características da criação de animais. No que diz respeito à produção vegetal, constatou-se que as atividades agrícolas se materializam em quatro culturas, banana, frutas, hortaliças e mandioca. Verificou-se também, que as hortaliças e as frutas estão presentes em todos os lotes, a cana, o eucalipto e a soja são culturas que ocupam consideráveis espaços territoriais, e o café não tem representatividade agrícola.

No grupo da Palha e no grupo de Produtores Individuais de Hortaliças, há uma predominância para o cultivo do milho. Já no grupo Pedra D'água, a soja é a cultura com maior reincidência, porém isto não significa que a soja seja a cultura mais importante para os assentados deste grupo. Nas entrevistas, os discursos evidenciaram que as hortaliças são os principais itens da comercialização. Por fim, no grupo dos Produtores que não Aderiram à Cana, verificou-se que 40,95\% do espaço agrícola são voltados à produção da cana, esta característica seria contraditória, podendo se explicar pela facilidade de irradiação da cana, apesar da resistência dos agricultores em se declararem produtores de cana. Demonstra também, a força de penetração desta cultura no assentamento decorrente das facilidades de comercialização e pela redução de esforços necessários à produção.

Constatou-se que a renda dos produtores está concentrada na comercialização de cinco culturas, as hortaliças (responsáveis por $25 \%$ do total), o milho com $18 \%$ da renda, a soja com $14 \%$, o eucalipto com $8 \%$ e a cana-de-açúcar com $28 \%$.

Traçando um panorama geral das escolhas dos assentados quanto à produção animal, pode-se constatar que há três opções mais frequentes no Assentamento Bela Vista, a criação de aves, suínos e bovinos. Os dados apontam que 36\% de toda a produção animal são referentes à criação de aves de corte, $35 \%$ à criação de aves de postura e 19\% à criação de suínos. A caracterização de cada grupo mostrou especificidades em relação ao sistema produtivo animal, por exemplo, percebeu-se que no Grupo Pedra D'água há duas espécies sendo criadas, as aves de postura que representam $53 \%$ do total de animais e os suínos que representam 47\%; já no grupo que não Aderiu à Cana concluiu-se, que a criação de aves de corte representa $36 \%$ do total do sistema produtivo, logo depois, tem-se a criação de aves de postura com $43 \%$, de suínos com $9 \%$, de bovino leiteiro com $5 \%$ e de bovino de corte com 7\%; no grupo da Palha, verificou-se que as aves de corte representam $52 \%$ da produção animal, as aves de posturas, $37 \%$, os suínos, $4 \%$, os bovinos leiteiros, $2 \%$ e os bovinos de corte, $5 \%$; por 
fim, constatou-se também, que no grupo de Produtores Individuais de Hortaliças, as principais criações são a de suínos $(63 \%)$, as aves de posturas $(13 \%)$, as aves de corte (12\%), os bovinos de corte $(9 \%)$ e os bovinos de leite $(3 \%)$.

Com relação ao sistema produtivo adotado, este tem características bastante heterogêneas, variando de criação para criação e de produtor para produtor. Vale destacar a utilização de diferentes materiais de construção nas instalações, assim como a diversidade genética dos animais e a utilização de diferentes matérias-primas para constituição da dieta dos animais. Ferrante, 1994, observou que em um assentamento, cada família que o constitui possui conhecimentos e práticas agrícolas diferentes. Neste mesmo sentido, Duval, Ferrante e Bergamasco (2012) pontuam que na agricultura familiar são empregadas diversas práticas agrícolas e técnicas experimentadas e vivenciadas ao longo da trajetória de cada agricultor, assim, cada assentamento apresenta características peculiares e próprias que o diferenciam dos demais. Investigou-se se a mesma informação é validada nos diferentes grupos que passam a compor os assentamentos. Desta forma, foram analisadas, comparativamente, as práticas agrícolas implantadas em cada lote, através de quatro variáveis, tratos fitossanitários; mecanismos para preparação do solo, controle de pragas e colheita.

Em relação à existência de um planejamento agrícola, constatou-se que todos os produtores, de todos os grupos produtivos, realizam no início de cada ano agrícola, um planejamento mínimo do sistema produtivo.

Na sequência, a pesquisa analisou o sistema de plantio, direto e/ou com descanso. Notou-se que em todos os grupos há uma predominância do sistema produtivo compulsivo. Logo depois, esta pesquisa avaliou os mecanismos para manejo do solo utilizados pelos assentados entrevistados. Numa visão geral verificou-se que $49 \%$ dos agricultores utilizam o herbicida, $24 \%$ lançam mão da roçadeira e $22 \%$ da capina manual.

Na avaliação da forma pela qual o solo é preparado, identificou-se que apenas dois grupos lançam mão da técnica de aração para preparar o solo, são eles o grupo de Produtores Individuais de Hortaliças e o grupo de Produtores que não Aderiram à Cana. Os mecanismos utilizados para a aração são: o arado de aiveca; carpideira tração animal de uma linha; soterrador; grade de disco; e arado de bacia ou disco. No que diz respeito aos tratos fitossanitários, constatouse a predominância do manejo convencional (com aplicação de venenos), relatado por $83 \%$ dos assentados, contra $17 \%$ que declaram manter um sistema tradicional. 
Outro ponto investigado foi o sistema de adubação e plantio. Constatou-se que para realizar a correção do solo, os agricultores do assentamento aplicam insumos, tais como calcário (23 agricultores utilizam este material), pó de rocha (quatro assentados). Os sete produtores do Grupo Individual de Hortaliças utilizam o calcário e um utiliza o pó de rocha; já o grupo Pedra D'água só aplica o calcário; o grupo que não Aderiu à Cana, por sua vez, aplica o calcário (cinco assentados entrevistados) e o pó de rocha (três entrevistados); já o grupo da Palha utiliza o calcário em cinco lotes dos entrevistados. Notou-se também, que o plantio das culturas se dá por meio de aquisição de sementes junto a fornecedores. Observou-se ausência de manipulação de sementes próprias em todos os grupos produtivos.

A caracterização do sistema de irrigação indicou que os agricultores entrevistados plantam culturas da época e quando há necessidade de irrigação, utilizam os métodos de aspersão e/ou gotejamento em todos os lotes entrevistados. Esta pesquisa questionou, também, a aplicação de adubos químicos. Isso porque, a busca de equilíbrio dos nutrientes é fundamental para o bom desempenho das plantas. Os resultados desta atividade são apresentados nas tabelas 2 e 3.

Estes dados da tabela mostram, mesmo sem serem explicitados, mecanismos próprios de agricultura tradicional sendo utilizados, ainda que em menor proporção. Há casos de assentados que se utilizam do sistema de cultivo "embolado", uma prática tradicional que pode dar bons resultados.

Outro ponto investigado foi o sistema de colheita. Conclui-se que parte da colheita é realizada por maquinário e parte é coletada manualmente. Os grupos que utilizam colhedora são os que não Aderiram à Cana e o grupo Individual de Hortaliças.

Por fim, analisou-se a existência ou não da plantação consorciada. A tabela 4 demonstra que o grupo Pedra D'água não implantou o sistema consorciado; o grupo de Produtores Individuais de Hortaliças tem 13\% de seus produtores praticantes da agricultura consorciada, este número eleva-se para $25 \%$ no grupo dos Produtores que não Aderiram à Cana e para 40\% no grupo da Palha. 
Tabela 2 - Aplicação do adubo pelos grupos entrevistados

\begin{tabular}{lcccc}
\hline \multicolumn{1}{c}{ Momento } & $\begin{array}{c}\text { Grupo de Produtores } \\
\text { Individuais de } \\
\text { Hortaliças }\end{array}$ & $\begin{array}{c}\text { Grupo } \\
\text { Pedra } \\
\text { D'água }\end{array}$ & $\begin{array}{c}\text { Grupo dos } \\
\text { Produtores que } \\
\text { não Aderiram à } \\
\text { Cana }\end{array}$ & $\begin{array}{c}\text { Grupo } \\
\text { da } \\
\text { Palha }\end{array}$ \\
\hline $\begin{array}{l}\text { No plantio; } \\
\begin{array}{l}\text { Durante o } \\
\text { desenvolvimento da } \\
\text { cultura; }\end{array}\end{array}$ & $44 \%$ & $66 \%$ & $30 \%$ & $33 \%$ \\
\hline
\end{tabular}

Tabela 3 - Frequência de uso de agrotóxico pelos agricultores

\begin{tabular}{llccc}
\hline $\begin{array}{c}\text { Frequência de } \\
\text { uso }\end{array}$ & $\begin{array}{l}\text { Grupo de Produtores } \\
\text { Individuais de } \\
\text { Hortaliças }\end{array}$ & $\begin{array}{l}\text { Grupo Pedra } \\
\text { D'água }\end{array}$ & $\begin{array}{l}\text { Grupos dos Produtores } \\
\text { que não Aderiram à } \\
\text { Cana }\end{array}$ & $\begin{array}{l}\text { Grupo da } \\
\text { Palha }\end{array}$ \\
\hline Às vezes & $80 \%$ & $67 \%$ & $70 \%$ & $83 \%$ \\
Sempre & $10 \%$ & $17 \%$ & $0 \%$ & $17 \%$ \\
Não respondeu & $10 \%$ & $16 \%$ & $30 \%$ & $0 \%$ \\
\hline
\end{tabular}


Tabela 4 -Análise do sistema produtivo agrícola sob a ótica do sistema consorciado.

\begin{tabular}{lcc}
\hline \multicolumn{1}{c}{ Grupo } & $\begin{array}{c}\text { Planta em } \\
\text { sistema } \\
\text { consorciado }\end{array}$ & $\begin{array}{c}\text { Não planta em } \\
\text { sistema consorciado }\end{array}$ \\
\hline Grupo da Palha & $40 \%$ & $60 \%$ \\
Grupo de Produtores Individuais de Hortaliças & $13 \%$ & $88 \%$ \\
Grupo Pedra D'água & $0 \%$ & $100 \%$ \\
Grupo dos Produtores que não Aderiram à Cana & $25 \%$ & $75 \%$ \\
\hline Visão geral do assentamento & $19 \%$ & $81 \%$ \\
\hline
\end{tabular}

\section{O que os dados revelam para o Assentamento Sepé Tiarajú}

Dada a grande diversidade de linhas de financiamento disponibilizadas aos assentados e produtores rurais, observou-se que no PDS Sepé Tiarajú, 74\% dos produtores lançaram mão de financiamento para implantar o sistema produtivo, $16 \%$ afirmaram ter implantado o sistema com recursos próprios e $10 \%$ preferiram não responder ao questionamento. A figura 3 elucida esta afirmação, cujos resultados são bem diferenciados em relação ao assentamento Bela Vista.

Figura 3 - Linhas de crédito acessadas pelos produtores assentados no Sepé Tiarajú.

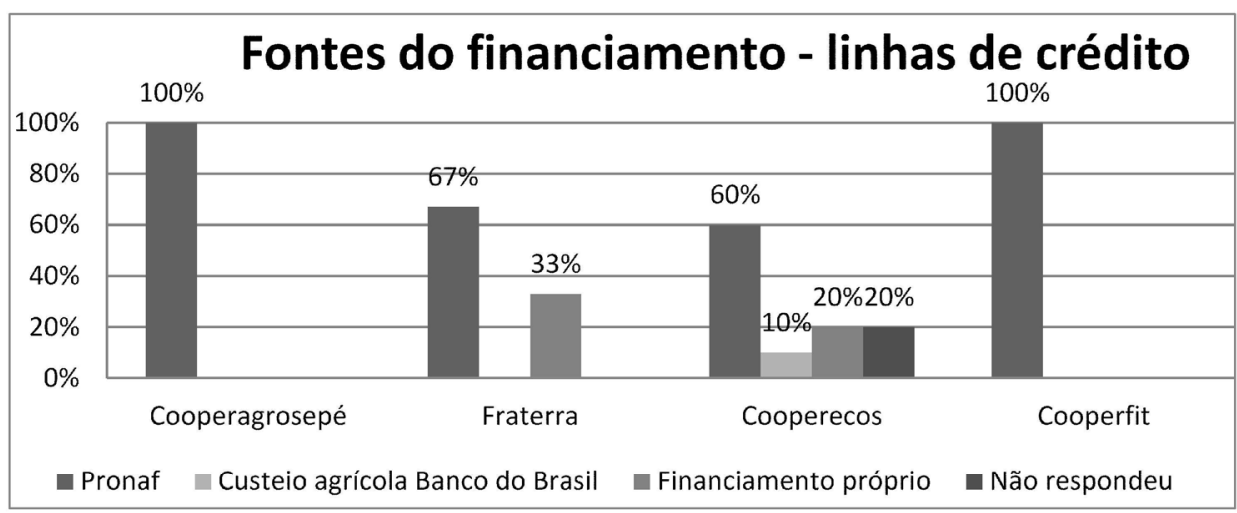


Outra variável investigada foi a política de assistência técnica. Constatou-se que a assistência técnica a qual os assentados tiveram acesso foi 100\% disponibilizada pelo INCRA e que todos os produtores investigados foram capacitados pela supracitada instituição.

Esta pesquisa analisou, também, as políticas de comercialização. Verificouse que a venda dos produtos produzidos no lote se efetiva por meio de programas institucionais. A figura 4 apresenta os programas que foram acessados por cada agricultor investigado e as respectivas proporções.

Figura 4 - Programas de apoio à comercialização acessada pelos grupos de produção investigados no PDS Sepé Tiarajú.

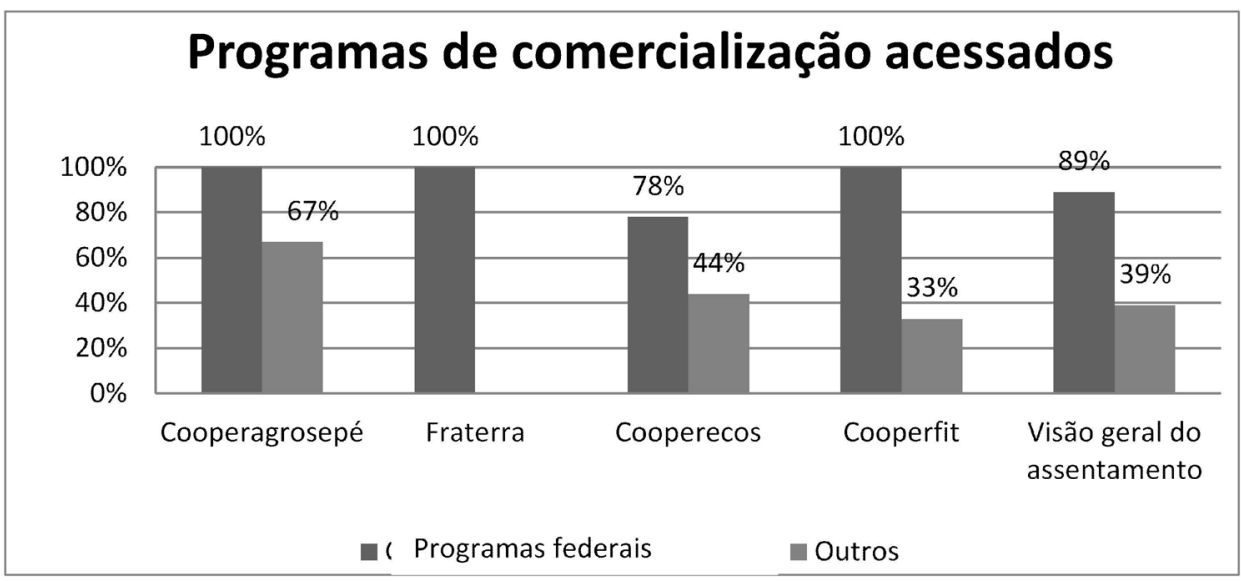

Em relação às políticas de infraestrutura social, tem-se na tabela 5 , a apresentação da síntese do nível de satisfação dos agricultores assentados em relação às políticas sociais ofertadas pelo poder público. 
Tabela 5 - Análise da oferta de políticas de infraestrutura social no assentamento Sepé Tiarajú.

\begin{tabular}{|c|c|c|c|c|c|}
\hline \multicolumn{6}{|c|}{ Nível de acesso } \\
\hline $\begin{array}{l}\text { Variável em } \\
\text { análise }\end{array}$ & $\begin{array}{l}\text { Cooperagrosepé } \\
\text { (3 membros) }\end{array}$ & $\begin{array}{c}\text { Fraterra } \\
\quad(3 \\
\text { membros })\end{array}$ & $\begin{array}{l}\text { Cooperecos } \\
(10 \text { membros })\end{array}$ & $\begin{array}{c}\text { Cooperfit } \\
(3 \\
\text { membros })\end{array}$ & $\begin{array}{c}\text { Visão geral } \\
\text { do } \\
\text { assentamento }\end{array}$ \\
\hline $\begin{array}{l}\text { Estrada em boas } \\
\text { condições }\end{array}$ & $100 \%$ & $100 \%$ & $90 \%$ & $100 \%$ & $95 \%$ \\
\hline $\begin{array}{l}\text { Transporte para a } \\
\text { cidade }\end{array}$ & $66 \%$ & $66 \%$ & $80 \%$ & $100 \%$ & $79 \%$ \\
\hline $\begin{array}{l}\text { Comunicação } \\
\text { telefônica/ }\end{array}$ & $66 \%$ & $100 \%$ & $90 \%$ & $100 \%$ & $89 \%$ \\
\hline Internet & $66 \%$ & $0 \%$ & $100 \%$ & $33 \%$ & $16 \%$ \\
\hline Educação & $100 \%$ & $66 \%$ & $90 \%$ & $100 \%$ & $89 \%$ \\
\hline
\end{tabular}

Observou-se, de uma forma geral, satisfação da comunidade nas questões educação, comunicação telefônica e estradas. No entanto, há uma insatisfação significativa nas questões relativas a posto de saúde e acesso à internet, dada a inexistência de oferta destes serviços.

OAssentamento Sepé Tiarajú, como referenciado na contextualização, foi criado em 2004, com a proposta de ser o primeiro assentamento agroecológico do Estado de São Paulo. Seu objetivo foi se constituir em um "Projeto de Desenvolvimento Sustentável" (PDS) que concilie o interesse social, econômico e ecológico(EMBRAPA, 2013). A concessão do uso da terra teve que obedecer à aptidão agrícola da área, combinada à vocação das famílias dos agricultores e ao interesse ecológico de recomposição vegetal, atendendo à legislação ambiental. Nesta experiência inovadora, a Agroecologia foi o centro da matriz tecnológica e a cooperação foi o eixo da organização produtiva (EMBRAPA, 2013). Estes princípios foram materializados, em um TAC (Termo de Ajustamento de Conduta), que apresentou orientações para o manejo dos solos e da água e de responsabilidades sociais e ambientais, propondo a conservação de $35 \%$ da extensão total do assentamento como Área de Reserva Legal (ARL), 15 pontos percentuais a mais do que rege a legislação vigente, mas que tecnicamente é recomendado para áreas de recarga do Aquífero Guarani (EMBRAPA, 2013).

Para a implantação do TAC, o PDS Sepé Tiarajú, implantou o Sistema Agroflorestal (SAF). Este sistema busca usar e ocupar o solo de forma a conciliar plantas lenhosas perenes (árvores, arbustos, palmeiras) com plantas herbáceas, culturas agrícolas e/ou forrageiras e/ou em integração com animais (ABDO, 
VALERI, MARTINS, 2008). Desta forma, se constataram os reflexos desta nova concepção de assentamento na execução do sistema produtivo - cultivo de vegetais e criação de animais.

A região onde está localizado o PDS Sepé Tiarajú, é caracterizada pela monocultura extensiva da cana-de-açúcar. A fim de modificar este cenário, e respeitar o TAC que o originou, o assentamento buscou alcançar a diversificação agrícola, fato que originou o cultivo do milho, mandioca, hortaliças, frutas, café e eucalipto. Notou-se que a maior extensão territorial é dedicada ao cultivo da mandioca (49\%), seguido da cultura do milho (25\%) e das frutas (24\%). A produção de hortaliças não teve a produção estimada em termos de extensão territorial.

É importante salientar que na Cooperativa Cooperagrosepé, a principal cultura é a mandioca (45,83\%), seguida do milho (25\%), frutas (25\%) e do café $(4,17 \%)$. $\mathrm{Na}$ Fraterra, as proporções são $45,75 \%$ da terra dedicada à cultura da mandioca, $15,24 \%$ ao cultivo do milho e $38,41 \%$ para a produção de frutas. Já na Cooperecos observou-se que a produção de mandioca se dá em 48,5\% do espaço territorial, a produção do milho é limitada em $27,76 \%$ do espaço territorial e a produção de frutas em $23,61 \%$. Por fim, na Cooperfit, tem-se que 55,51\% da área produtiva é dedicada ao cultivo da mandioca, 20,25\% para o milho, $17,64 \%$ para as frutas e $6,6 \%$ para o eucalipto.

As culturas implantadas e que estão em fase de produção, são as principais fontes de renda no assentamento Sepé Tiarajú, em média, as hortaliças proporcionam um faturamento de $\mathrm{R} \$ 830,00$ mensal para cada assentado.

Simultaneamente à produção vegetal, observou-se a existência da produção animal. Traçando um panorama geral das escolhas dos assentados quanto à produção animal, pôde-se constatar que há três opções mais frequentes no PDS, a criação de aves, suínos e bovinos. Os dados apontam que 49\% de toda a produção animal são referentes à criação de aves de corte, $45 \%$ à criação de aves de postura, $5 \%$ à criação de suínos, e $1 \%$ à criação de bovino leiteiro. A caracterização de cada grupo constatou particularidades em relação ao sistema produtivo animal, percebeu-se, por exemplo, que na Cooperativa Cooperagrosepé, as aves de corte representam 67\% da produção animal, enquanto que as aves de postura representam $31 \%$ e os suínos, $2 \%$. Na Fraterra, os dados contabilizados demonstraram que as aves de corte representam 33\%, as aves de postura $50 \%$, os suínos $8 \%$ e o bovino leiteiro, $9 \%$ de toda a criação animal existente. Já na Cooperecos, constatou-se maior proporcionalidade entre as criações de aves, $49 \%$ dos animais criados são aves de postura e $46 \%$ são 
aves de corte, os 5\% restantes correspondem à criação de suínos. A Cooperfit tem um perfil próximo à Cooperecos, onde $53 \%$ da produção animal se dá pela criação de aves de corte, $43 \%$ são aves de postura e os suínos representam $4 \%$. No geral, parte da produção animal é comercializada e parte compõe o quadro do autoconsumo. A produção animal dá ao assentamento um faturamento médio mensal de R $\$ 181,58$, sendo que as aves de corte são responsáveis pelo maior montante arrecadado.

Em relação ao sistema produtivo, percebeu-se que no Sepé Tiarajú, assim como no Bela Vista, os produtores realizam no início de cada ano agrícola, um planejamento mínimo. Logo depois, esta pesquisa avaliou os mecanismos para manejo do solo utilizados pelos assentados. Numa visão geral verificou-se que $83 \%$ dos agricultores lançam mão da roçadeira e da capina manual, outros $6 \%$ efetivam o preparo do solo com a tração animal.

Na sequência, a pesquisa buscou avaliar a forma pela qual o solo é preparado. Constatou-se que o principal maquinário utilizado por todos os agricultores é a grade de disco o que, tecnicamente é mais prejudicial à conservação do solo. No geral, os mecanismos utilizados para a aração são: o arado de aiveca (11\%); carpideira tração animal de uma linha $(22 \%)$; sucador de arrastro (11\%); grade de disco (78\%); e arado de bacia ou disco (6\%).

Outra variável analisada foram os tratos fitossanitários, constatou-se a predominância da adoção do manejo tradicional, relatado por $100 \%$ dos assentados.

A fim de analisar a veracidade das informações referentes ao controle de pragas e doenças, prosseguiu-se a investigação, analisando-se o sistema de adubação e plantio executado pelos agricultores. Constatou-se que para realizar a correção do solo, os agricultores do assentamento aplicam insumos, tais como calcário ( $45 \%$ dos agricultores utilizam este material); e pó de rocha (5\%). Observou-se, também que a Fraterra não faz aplicação de insumo algum, enquanto que a Cooperagrosepé e a Cooperfit utilizam apenas o calcário. Já a Cooperecos tem $40 \%$ dos entrevistados utilizando o calcário e $10 \%$ utilizando o pó de rocha. A pesquisa permitiu identificar ainda, pelos relatos dos agricultores, que a fertilização, em grande parte, se dá pelo uso de restos de plantas e adubos verdes. Ainda constatou-se, que esta prática, agregando-se ao fato de que grande parte dos lotes estão cobertos por restos de cultivos e ou por plantas espontâneas, leva também ao controle de pragas.

A caracterização do sistema de irrigação indicou que os agricultores plantam culturas da época e quando há necessidade de complementação, utilizam os 
métodos de aspersão e/ou gotejamento em todos os lotes. Outro ponto investigado, foi o sistema de colheita, inferiu-se que parte da colheita é realizada por maquinário e parte é coletada manualmente. Por fim, o último ponto analisado nesta seção foi a existência ou não da plantação consorciada, observou-se que $58 \%$ dos entrevistados plantam em sistemas consorciados.

\section{Conclusões}

Este artigo, embasado em pesquisa quali-quantativa, não teve como prioridade uma análise metodológica comparativa. Tem-se clareza de que há entre os dois assentamentos escolhidos para a investigação, um hiato de vinte e cinco anos e uma diferença institucional de modalidade, os quais contam significativamente. Entretanto, a escolha intencional de duas modalidades diferentes, de assentamentos - emblemáticos em um e outro caso distintos - favorece reflexões e contrapontos que não devem ser tomados metodologicamente como expressão de uma análise teórica de caráter comparativo. Sabe-se que além das conjunturas diferenciadas, a própria política de assentamento obedeceu a estratégias governamentais distintas.

A investigação pôde, de acordo com a singularidade dos dois estudos de caso, apontar problemas comuns, como os relativos ao perfil da assistência técnica, às dificuldades dos órgãos gestores, à constante falta de vontade política das prefeituras em inserir, de fato, os assentamentos na agenda política do desenvolvimento, aos preconceitos que, com exceções, ainda marginalizam os assentados.

São tais situações que exigiram que a abordagem adotada neste artigo não tivesse unicamente o enfoque econômico. A busca de conhecer um pouco mais a dinâmica dos grupos de produção, sistemas agrícolas exigiu a incorporação, na interpretação dos dados, de tensões, rupturas, resistências, nas quais formas alternativas de sobrevivência e permanência na terra vêm sendo incansavelmente buscadas, num movimento em que os arranjos familiares se modificam em função das necessidades de reprodução social destes sujeitos.

Salienta-se mais uma vez que há uma diferenciação bastante significativa de assentamentos antigos e novos em relação ao sistema produtivo. Apesar do desenvolvimento da horticultura estar sendo uma alavanca produtiva no caso do Bela Vista do Chibarro, percebe-se que os assentamentos das décadas de 1980, 1990, aqui denominados de assentamentos antigos estão mais inseridos nos sistemas agroindustriais do que os mais novos, para os quais conta decisivamente a inserção nos programas federais, PAA, PNAE que acabam se tornando 
estratégias produtivas e de comercialização das mais importantes.

Não existe uma fórmula final de sucesso ou insucesso dos PAs, mas há caminhos e exemplos importantes a serem seguidos que exigem nada mais do que uma boa articulação entre poder público federal - prefeituras municipais participativas que articulem projetos efetivos de geração de trabalho e renda e de qualidade de vida: gestores que em pouco tempo demonstrem perspectivas de eficácia dos programas, ainda que essa não seja a situação predominante. Neste sentido, os parâmetros de eficácia dirigidos a assentamentos têm que levar em conta as perspectivas de continuidade ou não de gestões públicas, o que pode gerar novos impasses.

Neste sentido é possível perceber que nos assentamentos em que o tempo de execução das políticas públicas foi realizado de forma mais ágil, no caso investigado, o assentamento Sepé Tiarajú, o desenvolvimento social e produtivo vem acontecendo mais rapidamente e a integração com as cidades é mais intensa. Este fato se dá porque os assentados deixam de ser vistos como "sem terra" e passam a ser reconhecidos como consumidores e produtores rurais.

Na maioria dos assentamentos que não receberam os créditos básicos como os fomentos, habitação, PRONAF ou sequer possuem infraestrutura básica como água e luz, o processo de desenvolvimento social e produtivo fica truncado. De forma genérica, pode-se dizer que a aplicabilidade das políticas públicas direcionadas à infraestrutura principalmente em assentamentos novos tem sido muito mais rápida no caso do crédito habitação e primeiros fomentos. Já em termos de infraestrutura básica como água, posto de saúde e escola, o processo é muito lento ou não tem acontecido.

A política de crédito, também revelou-se pouco eficiente, sendo o PROCERA, extinto há quinze anos, citado como o financiamento mais acessado no assentamento Bela Vista. Com relação à assistência técnica, os dados confirmam sua falta de efetividade - em termos de regularidade do serviço e capacidade de incentivar uma mudança cultural, a maioria dos assentados considera a ATER ruim.

A questão da assistência técnica foi apontada como uma atividade basicamente burocrática, especialmente pelo fato da pouca presença dos técnicos de campo nos lotes. Talvez a maior crítica em relação à assistência técnica esteja no fato do distanciamento dos funcionários do campo.

A temática ambiental - complexa e abrangente - pode ser identificada como um calcanhar de Aquiles (não necessariamente o único, mas o mais urgente) da política de assentamentos. Há situações premente a serem verificadas que envolvem não apenas questões ambientais como contaminação do solo ou 
superexploração/esgotamento dos aquíferos, mas uma questão de saúde pública.

De um lado, a criação dos PDS's, representa uma grande inovação pela recusa, firmada na lei e na prática, do uso de agrotóxico. De outro, há necessidade de se pensar em outras dimensões de degradação ambiental que vêm sendo enfrentadas em alguns PDS's e a inevitabilidade de se considerar que, diferentemente da Amazônia, São Paulo tem dificuldades concretas e falta de recursos de biodiversidade para explorar. Além disso, as discussões envolvendo o Termo de Ajustamento de Conduta mostram que há dilemas político-jurídicos a serem enfrentados pelos PDS's. De outro lado, a situação do Bela Vista, de predomínio da agricultura convencional, ainda é permeada pela "invasão" da cana, apesar da intensificação das atividades recentes de diversificação, o que impõe obstáculos à conquista da autonomia pelos assentados.

\section{Referências}

ABDO M. T. V. N.; VALERI S. V., MARTINS A. L. M. Sistemas agroflorestais e agricultura familiar: uma parceria interessante. Revista Tecnologia \& Inovação Agropecuária, São Paulo: ASPTA. 2008, p.5058. Disponível em: $<$ http://www.dge.apta.sp.gov.br/Publicacoes/T\&IA2/ T\&IAv1n2/Artigo_Agroflorestais_5.pdf >.Acesso em: 04 ago. 2014.

ALY JÚNIOR, O. Projetos de Desenvolvimento Sustentável (PDS'S) e os Desafios na Construção de Novas Politicas de Assentamento. Retratos de Assentamentos, Araraquara, v. 14, nº. 2, p. 283-303, 2011.

CAIRES, A. C. R. O assentamento Bela Vista do Chibarro em tempos anteriores: vida e trabalho na Usina Tamoio. Retratos de assentamentos, v. 14, n. 2, p. 95-131, 2011.

DUVAL, H. C; FERRANTE, V. L. S. B.; BERGAMASCO, S. M. P. P. Autoconsumo e as escalas de diversificação agrícola em um assentamento rural. Raízes, v.32, n.2, jul-dez / 2012.

EMBRAPA MEIO AMBIENTE. Assentamentos rurais sustentáveis: o processo de construção participativa do conhecimento agroecológico e o monitoramento de unidades de referência no Assentamento Sepé Tiarajú-SP. Brasília, 2013.47p. 
FERRANTE, V. L. S. B. (Org.). Retratos de Assentamentos. v. 9. Araraquara: UNIARA, 2004.

. Os Herdeiros da Modernização (Grilhões e Lutas dos Boias-

Frias). Revista São Paulo em Perspectiva, v. 8, p. 93-104, 1994.

GOMES, T. P. S.; FERRANTE, V. L. S. B. Políticas públicas entre eficácias, equívocos e omissões: um retrato em duas regiões do Estado. Retratos de Assentamentos, v. 15, p. 157-186, 2012.

INCRA/MDA - Ministério do Meio Ambiente /CNS - Conselho Nacional Dos Seringueiros. Projeto de desenvolvimento sustentável. Brasília, 2000. 50 p.

MAIA, P. O. PAA em um Projeto de Desenvolvimento Sustentável, Arranjos e Conflitos na produção e reprodução da vida: um estudo no assentamento Sepé Tiarajú, município de Serrana e Serra Azul-SP. Dissertação (Mestrado em Desenvolvimento regional e Meio Ambiente). Araraquara, 2013.

MORISSAWA, M. A história da luta pela terra e o MST. São Paulo: Expressão popular, 2001.

PESQUISA INCRA/UNIARA. Pesquisa derivada de um contrato de prestação de serviços (Contrato CRT/SP/No $100000 / 2010)$ que previu a contratação da Uniara, por meio do Mestrado em Desenvolvimento Regional e Meio Ambiente para serviços em assessoria em desenvolvimento nos assentamentos rurais e comunidades quilombolas do INCRA em todo o estado de São Paulo. Araraquara, 2011-2012.

RAMOS FILHO, L. O. (Org.). Agricultura, meio ambiente e inclusão social: Questões para debate. 1. ed. Jaguariúna - SP: Embrapa Meio Ambiente, 2006. 128p.

RAMOS FILHO, L.; SZMRECSÁNYI T.; PELLEGRINI, J. B. R. Biodiversidade e reforma agrária: uma experiência agroecológica na região 
canavieira de Ribeirão Preto - Brasil. Montreal, Canadá, 2007.

ROSIM, L. Nas terras da Usina, o fazer-se de um assentamento.

Dissertação de Mestrado- Programa de Sociologia -FCL/UNESP. Araraquara, 1997.

SCOPINHO, R. A. Em busca de "elos perdidos": projetos de assentamentos e modos de identificação entre trabalhadores rurais assentados. Cadernos de Psicologia Social do Trabalho, v. 12, n. 2, p. 257-270, 2009.

SCOPINHO, R. A. Processo organizativo de assentamentos rurais: trabalho, condições de vida e subjetividade. São paulo: Anaablume, 2012. $348 p$. 
